\title{
The Effects of Doping Copper and Mesoporous Structure on Photocatalytic Properties of $\mathrm{TiO}_{2}$
}

\author{
Yang Wang, ${ }^{1}$ Wubiao Duan, ${ }^{1}$ Bo Liu, ${ }^{1}$ Xidong Chen, ${ }^{1}$ Feihua Yang, ${ }^{2}$ and Jianping Guo ${ }^{2}$ \\ ${ }^{1}$ Department of Chemistry, School of Science, Beijing Jiaotong University, Beijing 100044, China \\ ${ }^{2}$ State Key Laboratory of Solid Wastes Resource Utilization and Energy Saving Building Materials, Beijing Building Materials Academy \\ of Sciences Research, Beijing 100041, China
}

Correspondence should be addressed to Wubiao Duan; wbduan@bjtu.edu.cn

Received 11 March 2014; Accepted 15 July 2014; Published 23 July 2014

Academic Editor: Do Kyung Kim

Copyright (C) 2014 Yang Wang et al. This is an open access article distributed under the Creative Commons Attribution License, which permits unrestricted use, distribution, and reproduction in any medium, provided the original work is properly cited.

\begin{abstract}
This paper describes a system for the synthesis of $\mathrm{Cu}$-doped mesoporous $\mathrm{TiO}_{2}$ nanoparticles by a hydrothermal method at relatively low temperatures. The technique used is to dope the as-prepared mesoporous $\mathrm{TiO}_{2}$ system with copper. In this method, the copper species with the form of $\mathrm{Cu}^{1+}$, which was attributed to the reduction effect of dehydroxylation and evidenced by X-ray photoelectron spectroscopy (XPS) and X-ray diffraction (XRD), was well dispersed in the optimal concentration 1 wt.\% Cu-doped mesoporous $\mathrm{TiO}_{2}$. In this as-prepared mesoporous $\mathrm{TiO}_{2}$ system, original particles with a size of approximately $20 \mathrm{~nm}$ are aggregated together to shapes of approximately $1100 \mathrm{~nm}$, which resulted in the porous aggregate structure. More importantly, the enhancement of the photocatalytic activity was discussed as effects due to the formation of stable $\mathrm{Cu}(\mathrm{I})$ and the mesoporous structure in the $\mathrm{Cu}$-doped mesoporous $\mathrm{TiO}_{2}$. Among them, Cu-doped mesoporous $\mathrm{TiO}_{2}$ shows the highest degradation rate of methyl orange (MO). In addition, the effects of initial solution $\mathrm{pH}$ on degradation of $\mathrm{MO}$ had also been investigated. As a result, the optimum values of initial solution $\mathrm{pH}$ were found to be 3 .
\end{abstract}

\section{Introduction}

Titanium dioxide $\left(\mathrm{TiO}_{2}\right)$ is the most widely used semiconductor as a stable photocatalyst, and its photocatalytic activity is mainly limited by the number of photogenerated electronhole pairs and their life. Although a lot of effort is being spent on improving these weaknesses, the efficient and effective method has yet to be developed.

The study found: doping metal ions not only can effectively reduce the band gap of $\mathrm{TiO}_{2}$ to increase the number of photogenerated electron-hole pairs; the doping metal ions can form the corresponding oxide space-charge layer to promote the photogenerated electron-hole pairs effective separation [1,2]. Sangpour et al. [3] modified $\mathrm{TiO}_{2}$ by $\mathrm{Au}, \mathrm{Ag}$, and $\mathrm{Cu}$ incorporation and showed that doping increases the probability of radical formation. The photoenhancement of the studied elements was determined in the following order: $\mathrm{Cu}: \mathrm{TiO}_{2}>\mathrm{Au}: \mathrm{TiO}_{2}>\mathrm{Ag}: \mathrm{TiO}_{2}>\mathrm{TiO}_{2}$. Park et al. [4] fabricated metal $\left(\mathrm{Co}^{2+}, \mathrm{Ni}^{2+}, \mathrm{Cu}^{2+}\right.$, and $\left.\mathrm{Zn}^{2+}\right)$ doped $\mathrm{TiO}_{2}$,
$\mathrm{Zn}$-doped $\mathrm{TiO}_{2}$, and $\mathrm{Cu}$-doped $\mathrm{TiO}_{2}$ which were found to be promising materials for the photocatalytic decomposition of methylene blue. Among various metallic doping elements, the copper doping has been proved to be a simple and effective way to increase the visible light absorption.

The construction of $\mathrm{TiO}_{2}$ nano- or microstructures with interesting morphologies and properties has recently attracted considerable attention. It is well known that ordered mesoporous materials with larger specific surface area, pore size, and the relatively regular channel structure are ideal materials for catalyst. Ordered mesoporous materials researched as photocatalysts for the treatment of environmental pollutants are one of the research hot spots in recent years [5]. Zhu et al. [6] prepared hierarchical mesoporous $\mathrm{TiO}_{2}$ microspheres with high crystallinity and high BET specific surface area. Comparing to P25, the degradation percentages by the mesoporous $\mathrm{TiO}_{2}$ microspheres are more than twice of those by P25. In the work of Xiong et al. [7], results showed that the polymeric template as well as 
calcination played an important role in tuning morphology, mesoporosity, and specific surface area of the synthesized mesoporous $\mathrm{TiO}_{2}$.

Considering the two aspects above and utilizing the existing knowledge in the area of nanometer metal oxides preparation, the $\mathrm{Cu}$-doped mesoporous $\mathrm{TiO}_{2}$ was prepared by a hydrothermal method at relatively low temperatures without calcination in this study. The chemical status of the main element was investigated with X-ray diffraction (XRD) and X-ray photoelectron spectroscopy (XPS). Particle size and pore structure were analyzed with electron microscopy photographs, laser particle size analyzer, and $\mathrm{N}_{2}$ adsorption and desorption isotherms. The light absorption band edge was characterized by means of UV-Vis diffuse reflectance spectroscopy. The photocatalytic activities of the as-prepared $\mathrm{Cu}$-doped mesoporous $\mathrm{TiO}_{2}$ were evaluated by photo degradation of methyl orange (MO).

\section{Experimental}

2.1. Preparation of Catalysts. Herein, all chemicals were used as received without further purification.

The triblock copolymer, Pluronic P123 ( $\mathrm{M}=5800$, Sinopharm Chemical Reagent Co., Ltd.), was used as the template. Tetrabutyl titanate (TBT, Sinopharm Chemical Reagent Co., Ltd., 97\%) was used as the titanium source and calculated amounts of $\mathrm{Cu}\left(\mathrm{NO}_{3}\right)_{2} \cdot 3 \mathrm{H}_{2} \mathrm{O}(\mathrm{M}=241.60$, Sinopharm Chemical Reagent Co., Ltd.) were chosen as the precursor of the dopant.

The synthesis of $\mathrm{Cu}$-doped mesoporous $\mathrm{TiO}_{2}$ was carried out with the following procedure according to the report [8].

$7.5 \mathrm{~mL}$ tetrabutyl titanate and $3 \mathrm{~g}$ triblock copolymer pluronic P123 were ultrasonically dispersed in $10 \mathrm{~mL}$ ethanol, labeled as solution A. And then $10 \mathrm{~mL}$ ethanol, $5 \mathrm{~mL}$ deionized water, $15 \mathrm{~mL}$ acetic acid, and $0.2 \mathrm{~g} \mathrm{Cu}\left(\mathrm{NO}_{3}\right)_{2} \cdot 3 \mathrm{H}_{2} \mathrm{O}$ were mixed to form a homogeneous solution, labeled as solution $\mathrm{B}$. The mixed solution, which was obtained by dropping solution A into solution B, should be stirred at room temperature for $1 \mathrm{~h}$ after mixing. Then the mixture was transferred to a $50 \mathrm{~mL}$ Teflon-lined stainless steel autoclave, followed by a hydrothermal treatment at $130^{\circ} \mathrm{C}$ for $24 \mathrm{~h}$. After the reaction, the powder sample was centrifuged, rinsed with ethanol and deionized water, and dried in vacuum at $80^{\circ} \mathrm{C}$ for $12 \mathrm{~h}$. After grinding, the product ( $1 \mathrm{wt} . \% \mathrm{Cu}$-doped mesoporous $\mathrm{TiO}_{2}$ ) just desired was obtained without calcination.

For comparison, unsupported catalyst pure $\mathrm{TiO}_{2}$ was also prepared using the same procedure without the addition of $\mathrm{P} 123$ or $\mathrm{Cu}\left(\mathrm{NO}_{3}\right)_{2} \cdot 3 \mathrm{H}_{2} \mathrm{O}$.

2.2. Characterization of Catalysts. The crystallite structures of the materials were investigated by analyzing the X-ray diffraction (XRD) patterns obtained with a RIGAKU Ru200B diffract meter equipped with $\mathrm{Cu}$ Ka irradiation with a fixed power source $(40 \mathrm{kV}, 40 \mathrm{~mA})$. Chemical compositions of the composites were analyzed using X-ray photoelectron spectroscopy (Thermo Scientific, ESCALAB 250Xi). The internal structures of the particles were studied with Transmission Electron Microscopy (TEM, JEOLJEM-2000
FX II). All the powders were ultrasonically dispersed in ethanol for $30 \mathrm{~min}$ prior to the measurement. And the surface features and morphologies of the synthesized materials were investigated with Scanning Electron Microscopy (SEM, JEOL JSM-6330F). The particle size distribution of the catalyst was examined using laser particle size analyzer (Malvern mastersizer2000). The specific surface area and pore size distribution were characterized by analyzing the $\mathrm{N}_{2}$ adsorption and desorption isotherms obtained at $-196^{\circ} \mathrm{C}$ using Quantachrome Quadrasorb SI automated surface area and pore size analyzer. All the materials were degassed at $150^{\circ} \mathrm{C}$ and $1.33 \times 10^{-4} \mathrm{~Pa}$ for $6 \mathrm{~h}$ prior to the measurement. UVVis diffuse reflectance spectroscopy (Hitachi U3900) with a wavelength scan range of $250-800 \mathrm{~nm}$ was used to determine the light absorption of the catalysts.

Throughout the subsequent discussion on catalyst characterization, $\mathrm{Cu}$-doped mesoporous $\mathrm{TiO}_{2}$ refers to $1 \mathrm{wt}$. \% $\mathrm{Cu}$-doped mesoporous $\mathrm{TiO}_{2}$.

2.3. Photocatalytic Activity Test. The photocatalytic activities of the catalysts on the degradation of methyl orange under visible light in aqueous solution were determined with the following procedure [9].

We used a beaker as the degradation pool, in which $50 \mathrm{ml}$ methyl orange aqueous solution (50 ppm) and $125 \mathrm{mg}$ as-prepared sample were mixed. Prior to irradiation, the mixture solution was shocked in the dark for $30 \mathrm{~min}$ until adsorption/desorption equilibrium was reached. The solution was then irradiated under visible light. A certain mixture solution was removed at regular intervals and filtered through a syringe filter $(0.45 \mu \mathrm{m})$. Finally, the degradation of methyl orange was analyzed by detecting the absorption at $462 \mathrm{~nm}$ using a UV-7504PC (CANY Shanghai). The xenon lamp (50 W, CEL-HXF300) was used to simulate the solar spectrum. The photocatalytic experiments were performed at $\mathrm{pH}$ 7 unless stated otherwise. When required, the initial $\mathrm{pH}$ values were adjusted to the desired values using $\mathrm{HCl}$ or $\mathrm{NaOH}$ solutions.

The photocatalytic activities of the pure $\mathrm{TiO}_{2}$ and mesoporous $\mathrm{TiO}_{2}$ were tested under the same experimental conditions.

\section{Results and Discussion}

3.1. XRD Characterization. The wide angle X-ray diffraction (XRD) patterns of $\mathrm{Cu}$-doped mesoporous $\mathrm{TiO}_{2}$ with different copper concentration were obtained and compared with pure $\mathrm{TiO}_{2}$ diffraction pattern in Figure 1. All of as-prepared $\mathrm{TiO}_{2}$ had (101), (004), (200), and (211) peaks at $2 \theta$ values of ca. $25.38^{\circ}, 37.82^{\circ}, 48.18^{\circ}$, and $54.4^{\circ}$, indicating that all of the asprepared $\mathrm{TiO}_{2}$ had an anatase crystal structure according to JCPDS-21-1272.

It must be noted that no copper species $\left(\mathrm{Cu}, \mathrm{CuO}, \mathrm{Cu}_{2} \mathrm{O}\right)$ were detected in the sample $1 \mathrm{wt} . \% \mathrm{Cu}$-doped mesoporous $\mathrm{TiO}_{2}$. The above observations may suggest that $\mathrm{Cu}$ was well dispersed in the $\mathrm{TiO}_{2}$. The similarity in the $\mathrm{Cu}$ and $\mathrm{Ti}$ ionic radii $(0.072 \mathrm{~nm}$ for $\mathrm{Cu}$ and $0.068 \mathrm{~nm}$ for $\mathrm{Ti}$ ) allows 


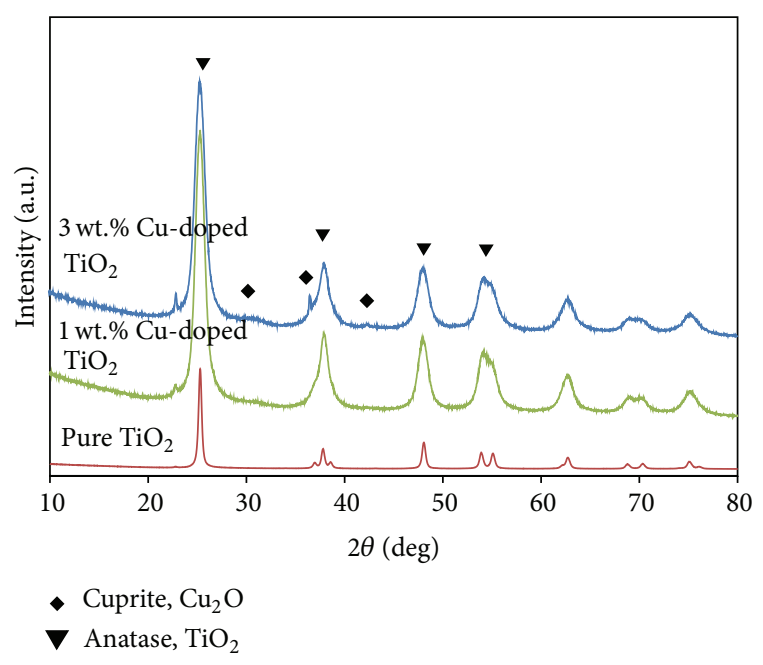

FIGURE 1: X-ray diffraction patterns of $\mathrm{Cu}$-doped $\mathrm{TiO}_{2}$ with different copper concentration and pure $\mathrm{TiO}_{2}$.

the interstitial incorporation of the dopant into the titania network.

In this section, we also provide a simple method for understanding of the copper species in the $\mathrm{Cu}$-doped mesoporous $\mathrm{TiO}_{2}$. The 3 wt.\% $\mathrm{Cu}$-doped mesoporous $\mathrm{TiO}_{2}$ with larger copper concentration was investigated, in which $\mathrm{Cu}_{2} \mathrm{O}$ crystal peaks were detected along with the anatase peaks of anatase $\mathrm{TiO}_{2}$, indicating that $\mathrm{Cu}$ phase dispersed in the form of micro- $\mathrm{TiO}_{2}$ crystal with $\mathrm{Cu}_{2} \mathrm{O}$ small clusters. It leads to the conclusion that the excess copper cannot replace $\mathrm{Ti}^{4+}$ entering into the $\mathrm{TiO}_{2}$ to form stable solid solution. Without special instruction, the optimal concentration of $1 \mathrm{wt} . \% \mathrm{Cu}-$ doped mesoporous $\mathrm{TiO}_{2}$ was used as the experimental sample in the following results and discussion.

Reading Huang et al.'s work [10] for reference, the formation of $\mathrm{Cu}_{2} \mathrm{O}$ may be due to acetic acid and ethanol, reducing $\mathrm{Cu}^{2+}$ to $\mathrm{Cu}^{1+}$. This reduction effect was attributed to the dehydroxylation step, where $\mathrm{OH}$ radicals with strong reducing proprieties were produced [11]. The presence of $\mathrm{Cu}^{1+}$ also corroborated with the following XPS results.

3.2. XPS Characterization. X-ray photoelectron spectroscopy (XPS) analysis can provide information about the oxidation states and compositions of the superficial metals, and to identify the chemical status of the main element in the samples.

Figure 2 shows the $\mathrm{X}$-ray photoelectron survey spectra of $\mathrm{Cu}$-doped mesoporous $\mathrm{TiO}_{2}$ composite. As can be seen, the XPS spectra pointed out that the copper has been successfully doped into the titanium dioxide structure.

Figure 3 shows the high resolution XPS spectra of Ti2p region and $\mathrm{Cu} 2 \mathrm{p}$ region for the $\mathrm{Cu}$-doped mesoporous $\mathrm{TiO}_{2}$. The peaks for Ti $2 \mathrm{p} 3 / 2$ and $\mathrm{Ti} 2 \mathrm{p} 1 / 2$, respectively, located at $458.58 \mathrm{eV}$ and $464.38 \mathrm{eV}$ are lower than those reported in the literature for the pure $\mathrm{TiO}_{2}$ at $458.9 \mathrm{eV}$ and $464.6 \mathrm{eV}$ [12]. Thus it means that there are more lattice defects that existed in the $\mathrm{Cu}$-doped mesoporous $\mathrm{TiO}_{2}$ lattice. Lattice defect

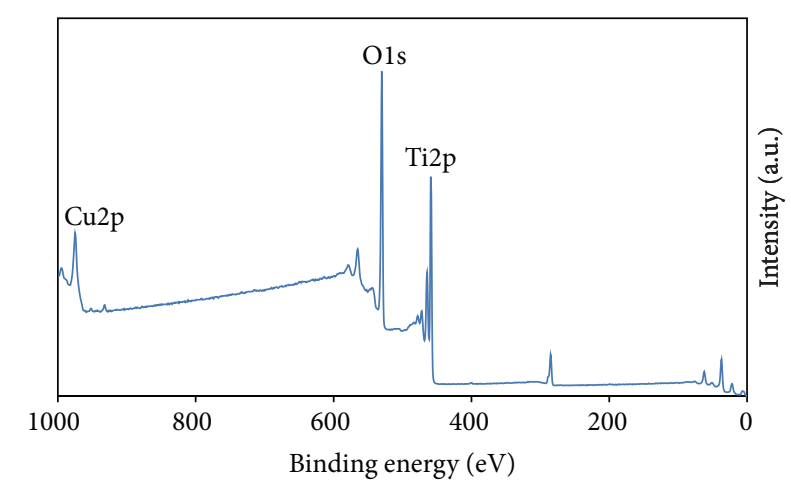

Figure 2: XPS survey spectra of Cu-doped mesoporous $\mathrm{TiO}_{2}$.

is active to capture photogenerated electrons and improve catalytic activity.

It is necessary to note that the $\mathrm{Cu} 2 \mathrm{p} 3 / 2$ level binding energy of about $932.2 \mathrm{eV}$ and $933.5 \mathrm{eV}$ is related to $\mathrm{Cu}_{2} \mathrm{O}$ and $\mathrm{CuO}$, respectively. And $\mathrm{Cu} 2 \mathrm{pl} / 2$ of $952.9 \mathrm{eV}$ and $953.6 \mathrm{eV}$ are related to $\mathrm{Cu}_{2} \mathrm{O}$ and $\mathrm{CuO}$, which are too close to distinguish.

The next steps are useful and innovative to make a distinction between $\mathrm{Cu}_{2} \mathrm{O}$ and $\mathrm{CuO}$. The high resolution XPS spectra of $\mathrm{Cu} 2 \mathrm{p}$ region for uncalcined (blue) and calcined (red) $\mathrm{Cu}$-doped mesoporous $\mathrm{TiO}_{2}$ were analyzed in Figure 4. After calcination in air at $450^{\circ} \mathrm{C}$, the $\mathrm{Cu} 2 \mathrm{p}$ peak broadened with the emergence of $\mathrm{CuO}$ characteristic peak in the red curve, indicating that the original $\mathrm{Cu}_{2} \mathrm{O}$ was oxidized. It can be concluded that loaded copper existed as oxidation state $\mathrm{Cu}_{2} \mathrm{O}$ in the $\mathrm{Cu}$-doped mesoporous $\mathrm{TiO}_{2}$ composite.

3.3. Particle Size and Pore Structure. As can be seen in Figure 5(a), the transmission electron microscopy image offers the information that the original particles are quite uniform and their size is about $20 \mathrm{~nm}$ but it is difficult to identify the channel structure, which can be attributed to that only a small portion of the sample was observed in the transmission electron microscopy analysis; moreover the sample was ultrasonically dispersed prior to observation. And in the scanning electron microscopy image of Figure 5(b), the aggregation of the original particles was observed and the size of aggregates is about $1000 \mathrm{~nm}$. In addition to electron microscopy analysis, the particle size distribution with statistical significance was analyzed as shown in Figure 6, and the average size of aggregates is about $1100 \mathrm{~nm}$, consistent with the SEM result.

With integrated analysis on results of the electron microscopy image and the particle size distribution, it can be concluded that the spherical nanocrystalline particles with a size of approximately $20 \mathrm{~nm}$ are aggregated together to shapes of approximately $1100 \mathrm{~nm}$, which resulted in the porous aggregate structure. More details on pore structure are discussed later in this chapter.

As can be seen in Figure 7, the $\mathrm{N}_{2}$ adsorption-desorption isotherms of pure $\mathrm{TiO}_{2}$, mesoporous $\mathrm{TiO}_{2}$ and $\mathrm{Cu}$-doped mesoporous $\mathrm{TiO}_{2}$ were investigated to evaluate the pore structure and pore size. The isotherms of the samples mesoporous $\mathrm{TiO}_{2}$ and $\mathrm{Cu}$-doped mesoporous $\mathrm{TiO}_{2}$ have classical 


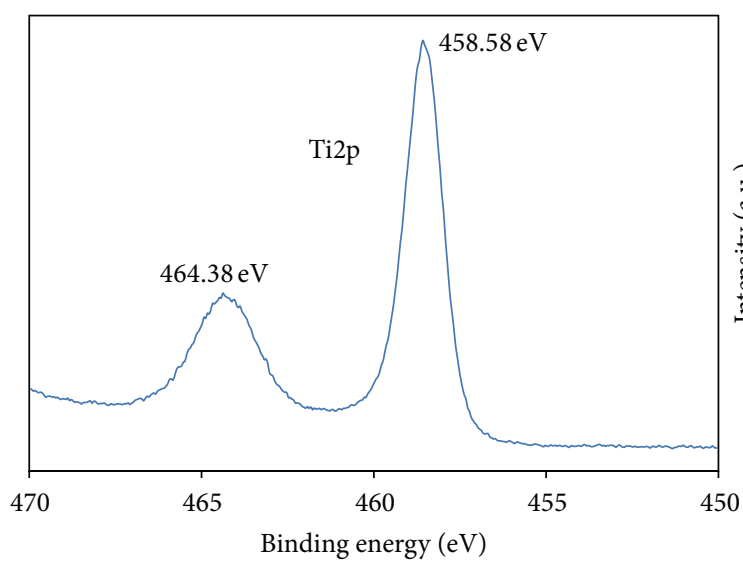

(a)

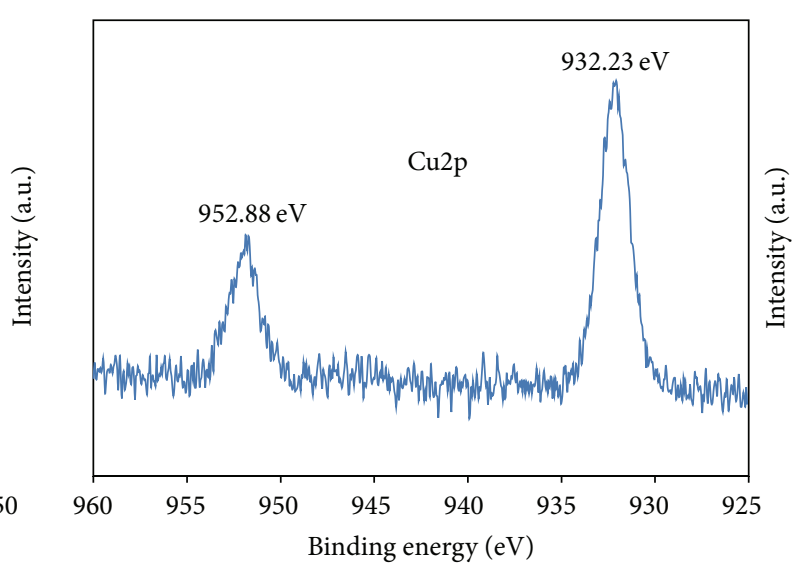

(b)

FIGURE 3: High resolution XPS spectra of Ti2p (a) region and $\mathrm{Cu} 2 \mathrm{p}$ (b) region for $\mathrm{Cu}$-doped mesoporous $\mathrm{TiO}_{2}$.

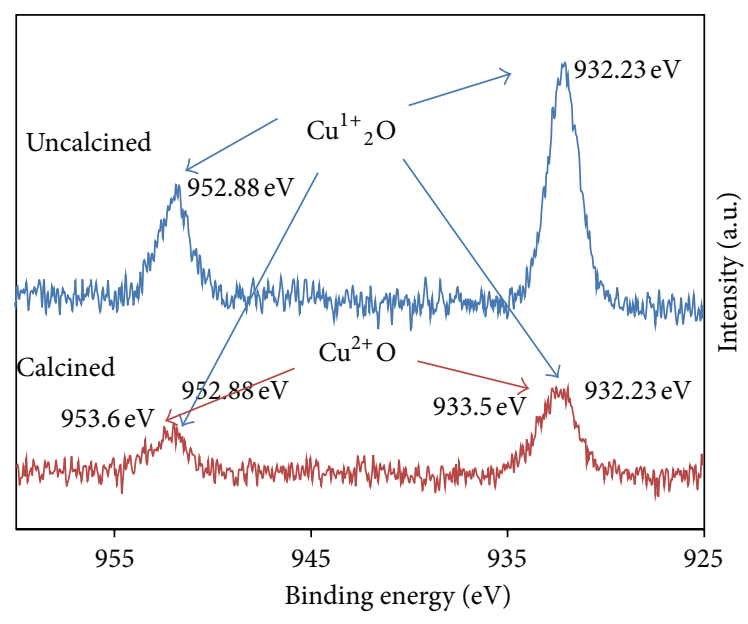

FIGURE 4: High resolution XPS spectra of $\mathrm{Cu} 2 \mathrm{p}$ region for uncalcined (blue) and calcined (red) $\mathrm{Cu}$-doped mesoporous $\mathrm{TiO}_{2}$.

hysteresis between the adsorption and desorption curves compared with pure $\mathrm{TiO}_{2}$, indicating the presence of pore structures. And the Brunauer Emmet Teller surface area $\left(\mathrm{S}_{\mathrm{BET}}\right)$ could be ranked as follows: $\mathrm{S}_{\mathrm{BET}}$ (mesoporous $\mathrm{TiO}_{2}$ ): $146 \mathrm{~m}^{2} / \mathrm{g}>\mathrm{S}_{\mathrm{BET}}\left(\mathrm{Cu}\right.$-doped mesoporous $\left.\mathrm{TiO}_{2}\right): 128 \mathrm{~m}^{2} / \mathrm{g}>$ $\mathrm{S}_{\mathrm{BET}}\left(\right.$ pure $\mathrm{TiO}_{2}$ ): $57 \mathrm{~m}^{2} / \mathrm{g}$. As can be seen, a narrow decrease has been identified for the copper-doped photocatalysts. That means copper doping will lead to the decrease of surface area due to the blockage of the pores by the copper oxide clusters [13].

3.4. Optical Properties. Cu-doped mesoporous $\mathrm{TiO}_{2}$ and pure $\mathrm{TiO}_{2}$ nanocomposites have been characterized by means of UV-Vis diffuse reflectance spectroscopy as shown in Figure 8. Compared with pure $\mathrm{TiO}_{2}$, absorption band edge of $\mathrm{Cu}$-doped mesoporous $\mathrm{TiO}_{2}$ was noticeably shifted toward the visible light region. According to the work developed by Li and Zhang [14], the expanded absorption band might be assigned to presence of $\mathrm{Cu}^{1+}$ clusters as well as the bulk $\mathrm{Cu}_{2} \mathrm{O}$.
Thus, it can be inferred that doping with a transition metal ion such as copper is effective for visible-light response and will play a significant role for enhancing the photocatalytic activity of the catalysts. However, excessive absorption of visible light and even infrared region will lead to a decline in photocatalytic oxidation ability. So it is important to tune the optical and electronic properties of semiconductor nanocrystals by controlling the type and concentration of dopant.

3.5. Photocatalytic Activity. The photocatalytic activities of the as-prepared $\mathrm{TiO}_{2}$ were evaluated by photo degradation of methyl orange. Figure 9 shows enhanced photocatalytic activity of $\mathrm{Cu}$-doped mesoporous $\mathrm{TiO}_{2}$ as well as that of pure $\mathrm{TiO}_{2}$ and mesoporous $\mathrm{TiO}_{2}$ under visible light irradiation.

The relationship of photocatalytic abilities among the catalysts was as follows: $\mathrm{Cu}$-doped mesoporous $\mathrm{TiO}_{2}>$ Mesoporous $\mathrm{TiO}_{2}>$ pure $\mathrm{TiO}_{2}$. A discussion of possible reasons for the enhanced photocatalytic activity of composite catalyst under visible light irradiation is summarized as follows. Firstly, the light absorption extended into visible light region due to copper doping. Secondly, $\mathrm{Cu}^{1+}$ acted as electron and hole trappers which could effectively reduce the photogenerated hole-electron recombination rate [15]. Finally, the higher adsorption of methyl orange onto the catalyst surface due to the mesoporous structures also played a role in enhancing the photocatalytic activity of composite catalyst.

Since $\mathrm{pH}$ play a vital role in the degradation of dyes and the $\mathrm{pH}$ values of the dyestuff waste could be different in practical application, additional experiments were carried out to examine the effects of initial $\mathrm{pH}$ values of methyl orange solution on the photocatalytic reaction. The catalyst used was the $\mathrm{Cu}$-doped mesoporous $\mathrm{TiO}_{2}$. The initial $\mathrm{pH}$ values of the test solution were in amplitude $\mathrm{pH}$ of 3-10 adjusted with $\mathrm{HCl}$ or $\mathrm{NaOH}$ without any modification during UV irradiation. All the other experimental conditions were identical [16].

Figure 10 demonstrated the degradation efficiency of methyl orange under different initial $\mathrm{pH}$ values of solution, 


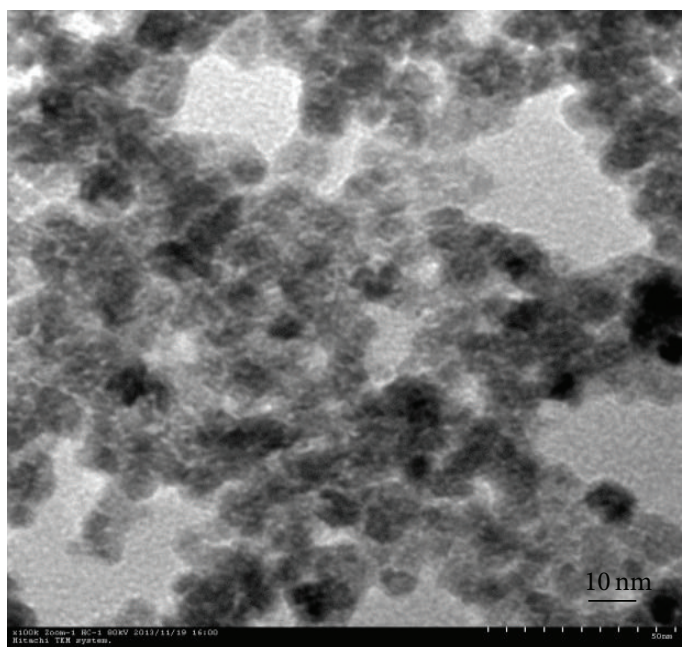

(a)

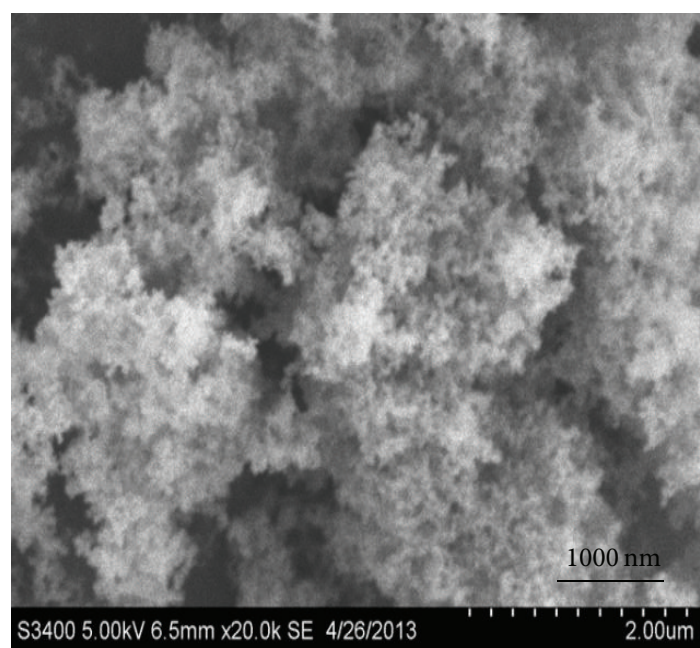

(b)

Figure 5: (a) TEM image of Cu-doped mesoporous $\mathrm{TiO}_{2}$; (b) SEM image of $\mathrm{Cu}$-doped mesoporous $\mathrm{TiO}_{2}$.

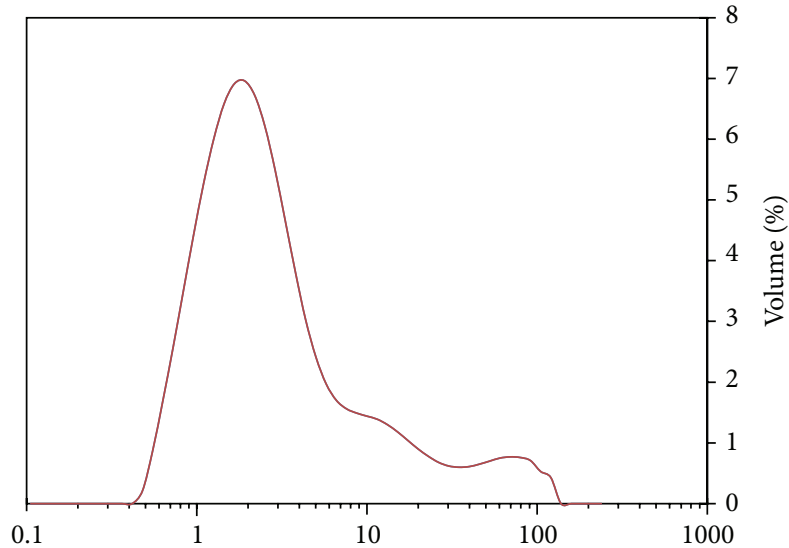

Figure 6: Particle size distribution of $\mathrm{Cu}$-doped mesoporous $\mathrm{TiO}_{2}$.

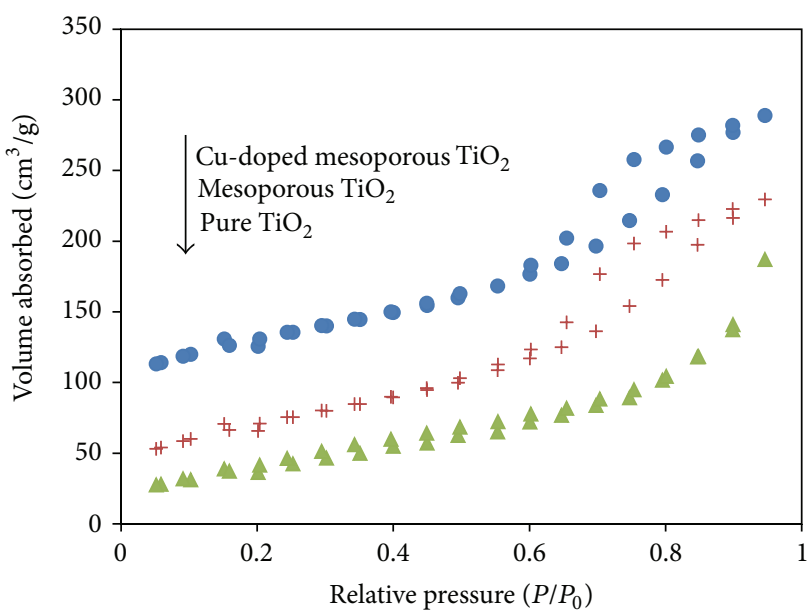

FIgURE 7: Nitrogen adsorption and desorption isotherms of pure $\mathrm{TiO}_{2}$, Mesoporous $\mathrm{TiO}_{2}$, and $\mathrm{Cu}$-doped mesoporous $\mathrm{TiO}_{2}$.

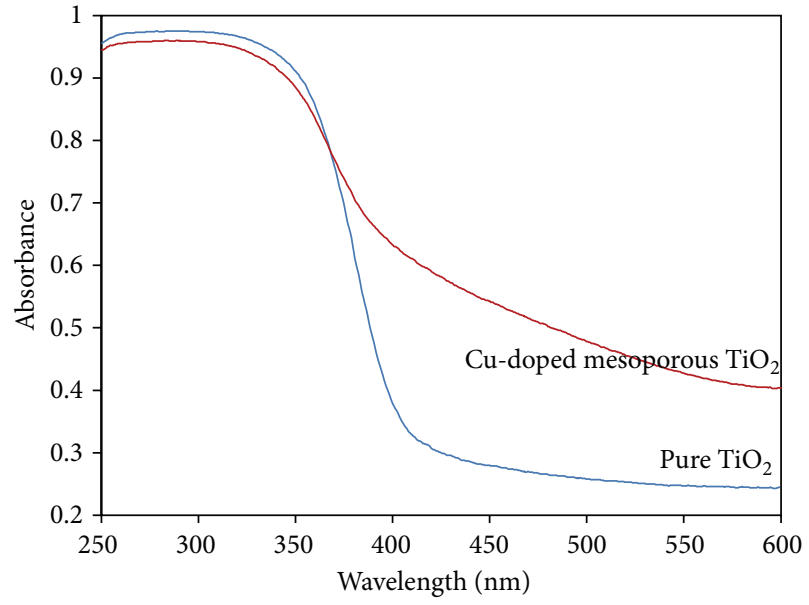

FIGURE 8: UV-Vis DRS of selected catalysts.

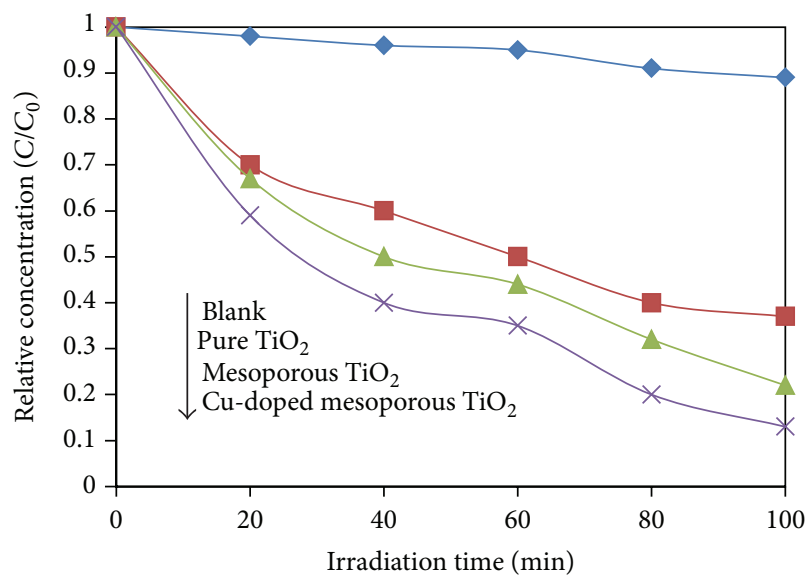

Figure 9: Photocatalytic degradation curves of pholocatalysts. 


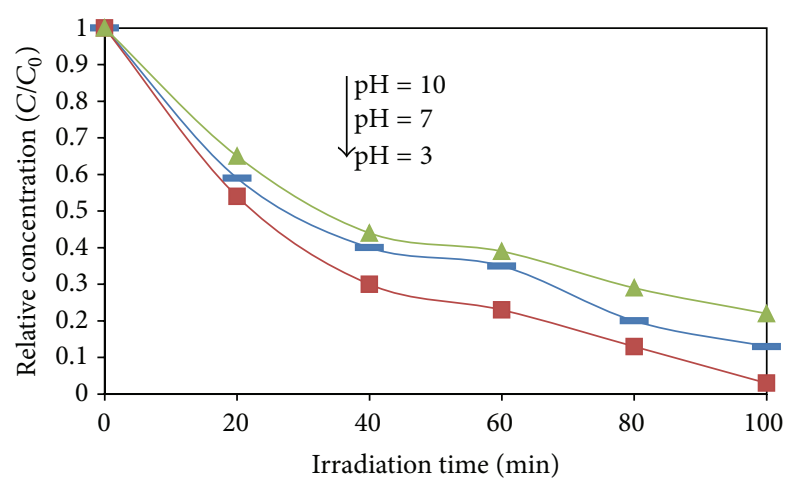

FIGURE 10: Effects of initial $\mathrm{pH}$ on the degradation of methyl orange by $\mathrm{Cu}$-doped mesoporous $\mathrm{TiO}_{2}$.

and a higher methyl orange degradation efficiency at acidic $\mathrm{pH}$ can be noticed. The reason that the photodegradation efficiency of $\mathrm{MO}$ depended on solution $\mathrm{pH}$ was due to the absorption/desorption of $\mathrm{MO}$ on $\mathrm{TiO}_{2}$ surface. In acidic solution, $\mathrm{TiO}_{2}$ was positively charged and absorbed $\mathrm{MO}$ molecules by electrostatic attraction; in alkaline solution, $\mathrm{TiO}_{2}$ was negatively charged and the absorption of MO molecules became weaker due to repulsive forces [17].

\section{Conclusions}

$\mathrm{Cu}$-doped mesoporous $\mathrm{TiO}_{2}$ was prepared by a hydrothermal method. The results confirmed that the high photocatalytic activity of as-prepared sample strongly depended on the stabilization of $\mathrm{Cu}$ (I) well dispersed in $\mathrm{TiO}_{2}$. Copper doping greatly enhanced the absorption in visible-light region and played a significant role for enhancing the photocatalytic activity of the catalysts. Moreover, mesoporous structures with larger specific surface area, pore size, and the relatively regular channel structure had better adsorption capacity.

\section{Conflict of Interests}

The authors declare that they have no financial and personal relationships with other people or organizations that can inappropriately influence their work, and there is no professional or other personal interest of any nature or kind in any product, service, and/or company that could be construed as influencing the position presented in, or the review of, this paper.

\section{Acknowledgments}

The authors would like to thank Beijing Jiaotong University and the State Key Laboratory of Solid Wastes Resource Utilization and Energy Saving Building Materials in Beijing Building Materials Academy of Sciences Research. This project was supported by the Fundamental Research Funds for the Central Universities (2014JBZ010) and the Project of Beijing Jiaotong University (no. 2012RC002). Yang Wang would also like to express his gratitude to all colleagues who provided assistance.

\section{References}

[1] H. W. P. Carvalho, M. V. J. Rocha, P. Hammer, and T. C. Ramalho, " $\mathrm{TiO}_{2}-\mathrm{Cu}$ photocatalysts: a study on the long- and short-range chemical environment of the dopant," Journal of Materials Science, vol. 48, no. 11, pp. 3904-3912, 2013.

[2] N. R. Khalid, E. Ahmed, Z. Hong, M. Ahmad, Y. Zhang, and $\mathrm{S}$. Khalid, "Cu-doped $\mathrm{TiO}_{2}$ nanoparticles/graphene composites for efficient visible-light photocatalysis," Ceramics International, vol. 39, no. 6, pp. 7107-7113, 2013.

[3] P. Sangpour, F. Hashemi, and A. Z. Moshfegh, "Photoenhanced degradation of methylene blue on cosputtered $\mathrm{M}_{\mathrm{TiO}}(\mathrm{M}=$ $\mathrm{Au}, \mathrm{Ag}, \mathrm{Cu}$ ) nanocomposite systems: a comparative study," The Journal of Physical Chemistry C, vol. 114, no. 33, pp. 13955-13961, 2010.

[4] J. Park, K. Choi, J. Lee, C. Hwang, and D. Choi, "Fabrication and characterization of metal-doped $\mathrm{TiO}_{2}$ nanofibers for photocatalytic reactions," Materials Letters, vol. 97, pp. 64-66, 2013.

[5] K. Nakata and A. Fujishima, " $\mathrm{TiO}_{2}$ photocatalysis: design and applications," Journal of Photochemistry and Photobiology C: Photochemistry Reviews, vol. 13, no. 3, pp. 169-189, 2012.

[6] L. Zhu, K. Liu, H. Li, Y. Sun, and M. Qiu, "Solvothermal synthesis of mesoporous $\mathrm{TiO}_{2}$ microspheres and their excellent photocatalytic performance under simulated sunlight irradiation," Solid State Sciences, vol. 20, pp. 8-14, 2013.

[7] B. Y. Xiong, W. F. Mao, P. F. Fang, and C. Q. He, "Evolution of mesostructures in titania upon template loading and calcination," Journal of Crystal Growth, vol. 380, pp. 28-33, 2013.

[8] S. Guo, S. Han, M. Haifeng et al., "Synthesis of phosphorusdoped titania with mesoporous structure and excellent photocatalytic activity," Materials Research Bulletin, vol. 48, no. 9, pp. 3032-3036, 2013.

[9] D. S. Kim, J. Jeon, and K. Shin, “The size-controlled synthesis of monodisperse spherical mesoporous $\mathrm{TiO}_{2}$ particles and high dispersions of $\mathrm{Pt}, \mathrm{Pd}$, and Ag clusters on their surfaces," Microporous and Mesoporous Materials, vol. 181, pp. 61-67, 2013.

[10] L. Huang, F. Peng, H. Yu, and H. Wang, "Synthesis of $\mathrm{Cu}_{2} \mathrm{O}$ nanoboxes, nanocubes and nanospheres by polyol process and their adsorption characteristic," Materials Research Bulletin, vol. 43, no. 11, pp. 3047-3053, 2008.

[11] R. López, R. Gómez, and M. E. Llanos, "Photophysical and photocatalytic properties of nanosized copper-doped titania sol-gel catalysts," Catalysis Today, vol. 148, no. 1-2, pp. 103-108, 2009.

[12] L. Ye, S. Wang, H. You, J. Yao, and X. Kang, "Photocatalytic reduction of perchlorate in aqueous solutions in $\mathrm{UV} / \mathrm{Cu}$ $\mathrm{TiO}_{2} / \mathrm{SiO}_{2}$ system," Chemical Engineering Journal, vol. 226, pp. 434-443, 2013.

[13] P. L. Richardson, M. L. N. Perdigoto, W. Wang, and R. J. G. Lopes, "Heterogeneous photo-enhanced conversion of carbon dioxide to formic acid with copper- and gallium-doped titania nanocomposites," Applied Catalysis B: Environmental, vol. 132133, pp. 408-415, 2013.

[14] L. Li and M. Zhang, "Preparation, characterization, and photocatalytic property of $\mathrm{Cu}_{2} \mathrm{O}-\mathrm{TiO}_{2}$ Nanocomposites," International Journal of Photoenergy, vol. 2012, Article ID 292103, 4 pages, 2012. 
[15] M. G. Sorolla, M. L. Dalida, P. Khemthong, and N. Grisdanurak, "Photocatalytic degradation of paraquat using nano-sized $\mathrm{Cu}$ $\mathrm{TiO}_{2} / \mathrm{SBA}-15$ under UV and visible light," Journal of Environmental Sciences, vol. 24, no. 6, pp. 1125-1132, 2012.

[16] H. Li, L. Cao, W. Liu, G. Su, and B. Dong, "Synthesis and investigation of $\mathrm{TiO}_{2}$ nanotube arrays prepared by anodization and their photocatalytic activity," Ceramics International, vol. 38, no. 7, pp. 5791-5797, 2012.

[17] J. L. Blin, M. J. Stébé, and T. Roques-Carmes, "Use of ordered mesoporous titania with semi-crystalline framework as photocatalyst," Colloids and Surfaces A, vol. 407, pp. 177-185, 2012. 

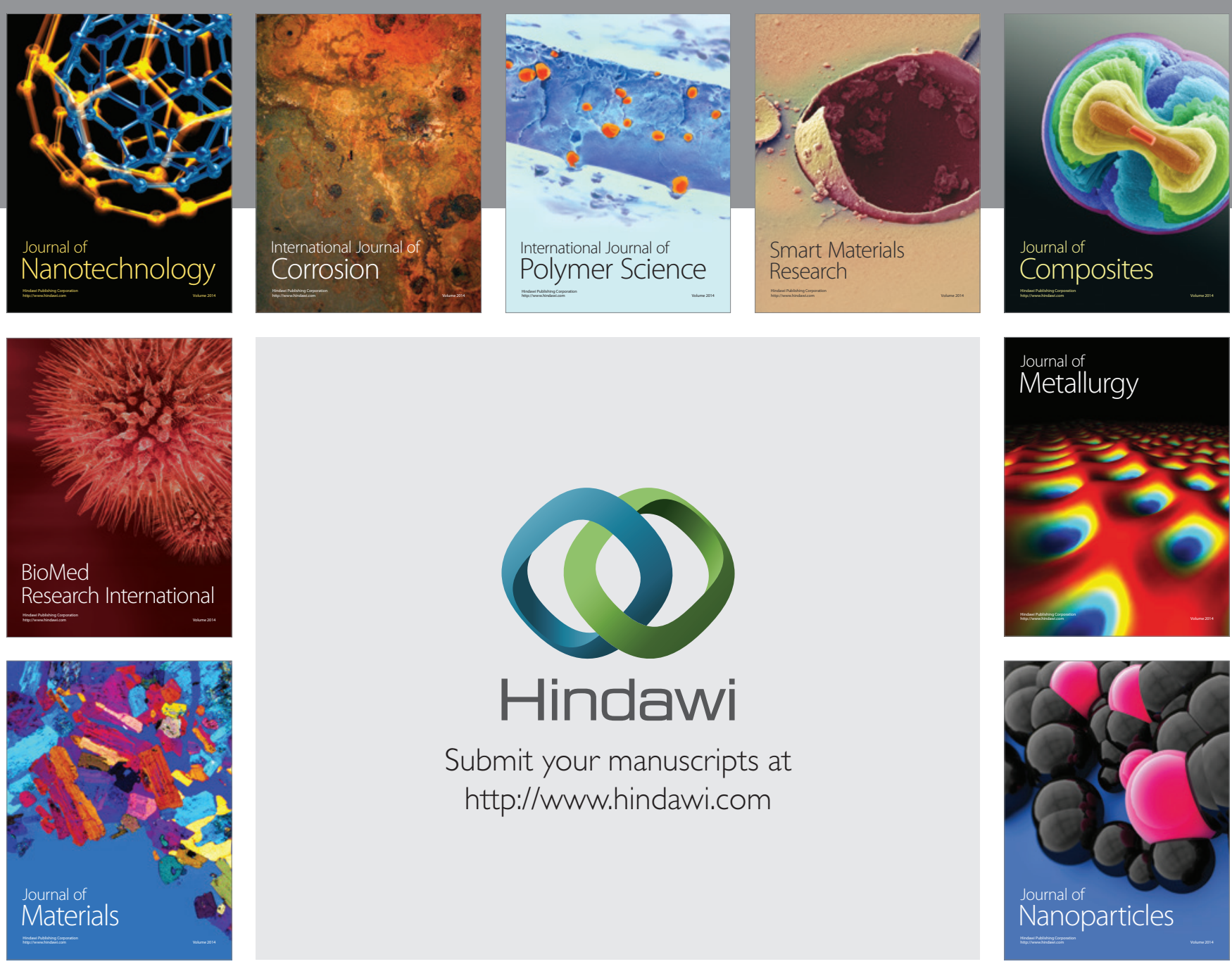

Submit your manuscripts at http://www.hindawi.com
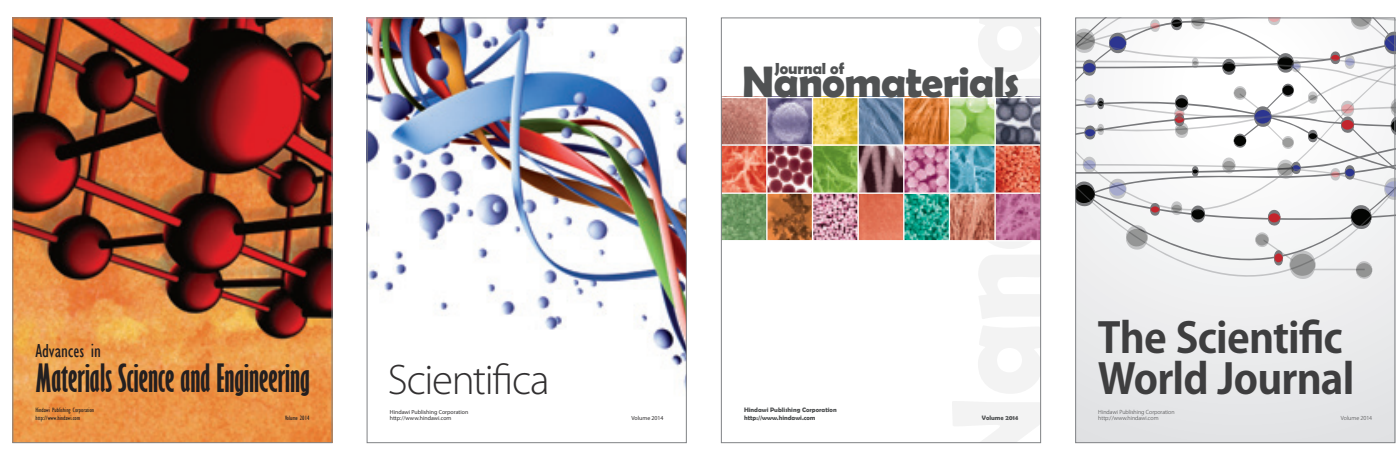

\section{The Scientific World Journal}
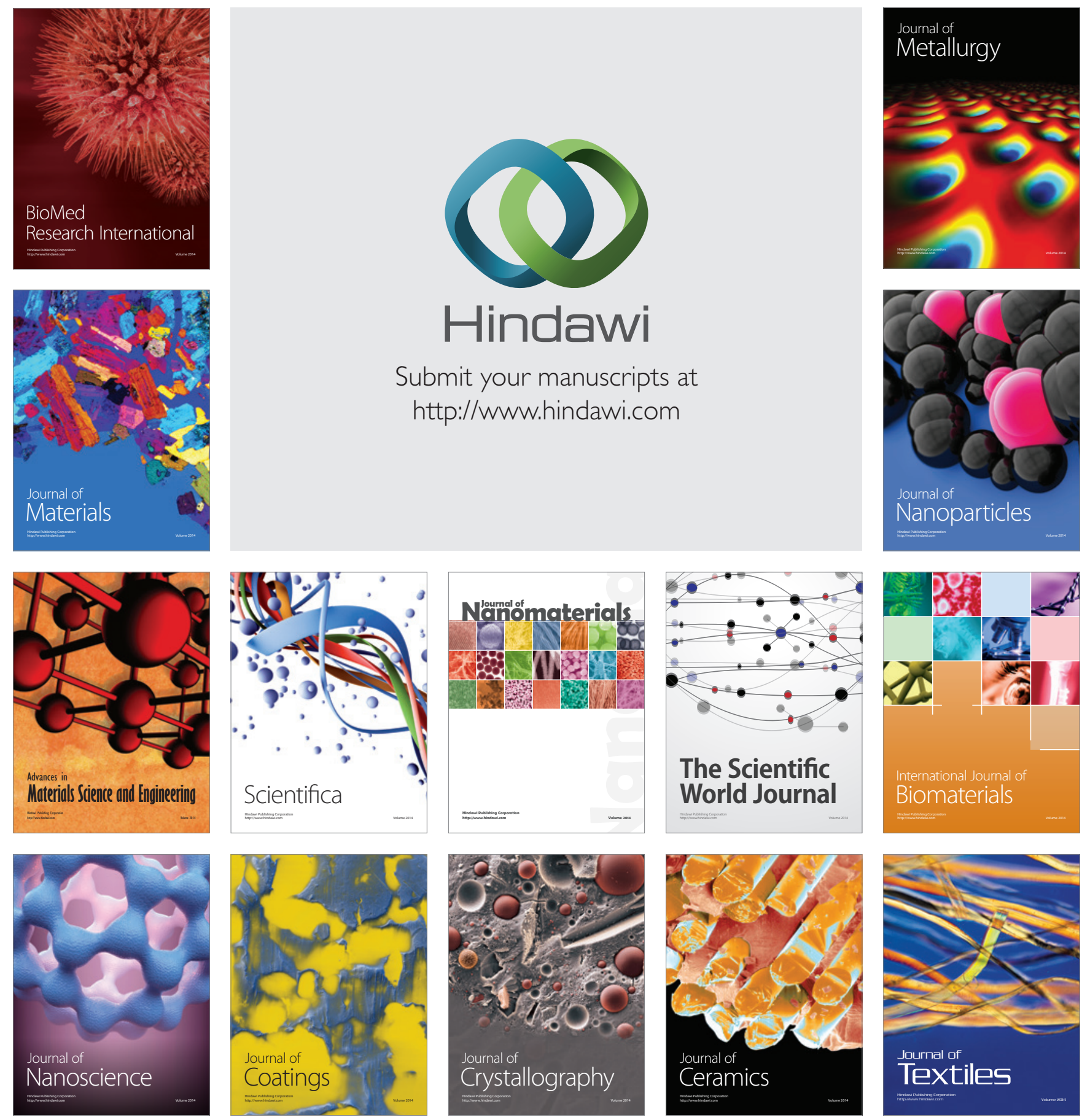